\title{
Microsurgical resection of unruputured Spetzler-Ponce grade A arteriovenous malformations is worthwhile and still the "gold standard" therapy
}

\author{
Torstein R. Meling ${ }^{1}$
}

Received: 31 May 2015 / Accepted: 8 June 2015 /Published online: 21 June 2015

(C) Springer-Verlag Wien 2015

In their article, "Microsurgical resection of Spetzler-Martin grade 1 and 2 unruptured brain arteriovenous malformations results in lower long-term morbidity and loss of Quality Adjusted Life Years (QALY) than conservative management - results of a single group series", Steiger and colleagues performed a single-centre, retrospective study of 97 patients who underwent microsurgical resection of unruptured brain arteriovenous malformations (AVMs), focusing on postoperative morbidity and lifetime loss of QALYs. The study demonstrates that microsurgical removal of unruptured SpetzlerMartin grade 1 and 2 AVMs produced more favourable long-term results than the modelled natural history, while surgical treatment of Spetzler-Martin grade 3 and 4 AVMs did not. The authors also studied the effect of age, as younger age may confer a certain advantage with respect to recovery from postoperative neurological deficits. They found that patients younger than 39 years tended to fare better after microsurgical treatment than older patients.

This is a very thorough and well-written article that fits nicely into the current debate after the ARUBA trial (1). In the ARUBA trial, different treatment modalities were lumped together and only a minority of patients were treated by microsurgery (5\%), despite $68 \%$ of the enrolled patients harboured brain AVMs of Spetzler-Martin grades 1 or $2(2,3)$. In contrast, this article focuses on the "gold standard" therapy of Spetzler-Martin grade 1 and 2 brain AVMs - namely, microsurgery. However, even in this article, preoperative embolisation was performed in $48 \%$ of patients prior to microsurgical resection. Thus, the complication rates reflect a

Torstein R. Meling

torsteinrmeling@gmail.com

1 The National Hospital of Oslo, Oslo, Norway composite of the two, and not just microsurgery, but given the retrospective nature of this study, it is probably impossible to separate the two.

The overall persisting morbidity rate of $10 \%$ is commendable, but in line with $11 \%$ in the published series by Bervini et al. (4). There are two important aspects here: one is that this rate is a far cry from the one found in the ARUBA trial (2), which was $50 \%$ higher than expected by the investigators and 5-6 times that found in a recent meta-analysis totalling 13,698 and 46,314 patient-years' follow-up (5). The second is that the $10 \%$ morbidity rate is an average and that $29 \%$ of the patients treated in this current series had Spetzler-Martin grade 3 and 4 AVMs. As the discussion of whether or not to treat unruptured AVMs progresses after the ARUBA trial, I think it is prudent to "keep the different animals apart", in that analyses should be performed separately for the low and high Spetzler-Martin grades, or better yet, start using the Spetzler-Ponce grading system $(6,7)$. As this study nicely demonstrates, microsurgical resection of Spetzler-Ponce grade A AVMs is worthwhile and not futile, although it comes at some risk, and by not offering the gold standard therapy to young patients with such AVMs, we may very well do them a great disservice.

\section{References}

1. Mohr JP, Parides MK, Stapf C, Moquete E, Moy CS, Overbey JR, Al-Shahi Salman R, Vicaut E, Young WL, Houdart E, Cordonnier C, Stefani MA, Hartmann A, von Kummer R, Biondi A, Berkefeld J, Klijn CJ, Harkness K, Libman R, Barreau X, Moskowitz AJ, International ARUBA investigators (2014) Medical management with or without interventional therapy for unruptured brain arteriovenous malformations (ARUBA): a multicentre, non-blinded, randomised trial. Lancet 383(9917):614-621

2. Meling TR, Proust F, Gruber A, Niemela M, Regli L, Roche PH, Vajkoczy P (2014) On apples, oranges, and ARUBA. Acta Neurochir (Wien) 156(9):1775-1779 
3. Proust F, Roche PH, Meling TR (2014) Does ARUBA study improve our knowledge as regards the management of unruptured brain arteriovenous malformations? Neurochirurgie 60(1-2):2-4

4. Bervini D, Morgan MK, Ritson EA, Heller G (2014) Surgery for unruptured arteriovenous malformations of the brain is better than conservative management for selected cases: a prospective cohort study. J Neurosurg 121(4):878-890

5. van Beijnum J, van der Worp HB, Buis DR, Al-Shahi Salman R, Kappelle LJ, Rinkel GJ, van der Sprenkel JW, Vandertop WP, Algra
A, Klijn CJ (2011) Treatment of brain arteriovenous malformations: a systematic review and meta-analysis. JAMA 306(18):2011-2019

6. Korja M, Bervini D, Assaad N, Morgan MK (2014) The role of surgery in the management of brain arteriovenous malformations: a prospective cohort study. Stroke 45(12):3549-3555

7. Spetzler RF, Ponce FA, Neurosurg C a J (2011) A 3-tier classification of cerebral arteriovenous malformations. Clinical article. J Neurosurg 114(3):842-849 